\title{
High-Temperature Deformation and Low-Temperature Fracture Behavior of Steel Slag Rubber Asphalt Mixture Surface Layer
}

\author{
Zhiqiang Shu ${ }^{1}$, Jianmin $\mathrm{Wu}^{1, *}$, Shi Chen ${ }^{2}$, Shan $\mathrm{Yi}^{2}$ and Shaoqing $\mathrm{Li}^{1}$ \\ ${ }^{1}$ Key Laboratory of Special Area Highway Engineering of Ministry of Education, Changan University, Xi'an, 710064, China \\ ${ }^{2}$ China State Railway Investment Construction Group Co., Ltd., Beijing, 102600, China \\ *Corresponding Author: Jianmin Wu. Email: wujm@chd.edu.cn
}

Received: 30 March 2021 Accepted: 25 May 2021

\begin{abstract}
Steel slag is regarded as one of the most widespread solid by-products of steel smelting with little commercial value. It can play a vital role in the construction industry especially in the field of transportation infrastructure construction. However, there are few evaluation systems established on the high-temperature deformation and low-temperature fracture behavior of steel slag rubber asphalt mixture (SSRAM). This study explores the performance of SSRAM by uniaxial penetration test, Semi-Circular Bending (SCB) test and evaluates test data through regression analysis. The uniaxial penetration test results shows that the failure deformation of SSRAM increases with the increase of steel slag content. According to the minimum allowable permanent deformation $\left(\mathrm{R}_{\mathrm{TS} \text {-min }}\right)$, the deformation of SSRAM should be controlled within $3 \mathrm{~mm}$. Meanwhile, the cracking index of the SSRAM surface layer calculated at low temperature can meet the design requirements. The SCB test results show that the stress peak degradation rate (specimens with $10 \mathrm{~mm}$ notch are compared with $0 \mathrm{~mm}$ ) of SSRAM with $40 \%$ steel slag content is $20.04 \%$. That means proper steel slag content makes the stress peak degradation rate of SSRAM reaches the lowest value. The calculation results of fracture energy density $\left(\mathrm{J}_{1 \mathrm{C}}\right)$ show that the steel slag additive reduced the fracture energy density of SSRAM. However, it is still proved that SSRAM with 40\% steel slag has the best lowtemperature fracture performance based on critical fracture toughness $\left(\mathrm{K}_{1 \mathrm{C}}\right)$ and fracture stress peak. Furthermore, the crack propagation velocity parametric equation of SSRAM is proposed through fracture mechanics theory and the increase of velocity is exponential. Considering the high-temperature deformation resistance and low-temperature fracture property, the SSRAM surface layer with $40 \%$ steel slag content showed a batter application potential.
\end{abstract}

\section{KEYWORDS}

Steel slag; asphalt mixture; uniaxial penetration test; SCB test; deformation resistance; crack propagation velocity

\section{Introduction}

Steel slag is regarded as one of the most widespread solid by-products of steel smelting, and it has been regarded as a challenge to environmental management in countries worldwide owing to the low recovery rate (less than 50\%). Thus, a series of environmental issues are caused, such as land occupation, and groundwater pollution, which in turn endangers human health [1]. Previous studies have extensively confirmed that the application of steel slag in the field of construction materials possesses considerable ecological benefits. 
In recent years, industrial by-products have played a crucial role in the road industry. For example, concrete with steel slag material can perform higher durability, mechanical properties. Compared to nature stone, steel slag has a larger specific surface area, and steel slag has a stronger interaction with asphalt [2]. In China, more than $90 \%$ of highways were constructed with asphalt pavements, which make the researches on steel slag asphalt mixture more important.

Numerous studies were conducted on steel slag which used in asphalt mixture, Ziaee et al. selected Electric Arc Furnace Slag (EAFS) as coarse aggregates in Warm Mix Asphalt (WMA) mixtures, and their test results showed that EAFS can improve the mechanical properties of WMA mixtures [3]. Ren et al. [4] proposed a method to characterize the combustion degree and evaluate the flame-retardant performance of the steel slag asphalt concrete, it was found that steel slag asphalt concrete has excellent flame-retardant performance and is a suitable choice for tunnel pavement. The proper content of steel slag would improve the indirect tensile strength [5], high-temperature performance [6], low-temperature fatigue life [7,8], and it is far from that. Shu et al. studied the road performance, thermal conductivity, and temperature distribution of steel slag rubber asphalt surface layer [9]. However, previous studies were not further discussed the high-temperature deformation resistance and low-temperature fracture behavior of steel slag rubber asphalt mixture, and there is little research on the crack propagation velocity in steel slag asphalt mixture.

Over the past few decades, many investigation methods for asphalt mixtures was developed to evaluate the permanent deformation of asphalt mixtures, such as indirect tensile strength, Laboratoire Central des Ponts et Chaussees (LCPC) wheel tracking [10], static creep, dynamic modulus, and repeated load permanent deformation tests et al [11,12]. Chen et al. [13] used a uniaxial penetration test to characterize the shear resistance of hot-mix asphalt (HMA) mixtures at high temperature. $\mathrm{Su}$ et al. developed a mechanistic-empirical model for predicting rutting in flexible pavements, which consider rutting resistance of pavement structure and materials by using uniaxial penetration test. This test was based on sound mechanistic principles efficiently considering shear factors, which employed shear strength to evaluate the deformation resistance of asphalt mixtures [14]. The latest specifications (JTG D50-2017) in China came into effect in 2017. Following Appendix F of JTG D50-2017, a uniaxial penetration test can be widely used in the process of evaluating the permanent deformation resistance of asphalt mixture.

The fracture phenomenon can be emerged in asphalt pavement, especially under a low-temperature environment. Marshall test or field sampling are widely used to conduct indirect tensile test (IDT), which was usually adopted to evaluate the anti-cracking performance of HMA at intermediate and low temperatures [15,16]. Birgisson et al. [17] investigated the cracking behavior of HMA by three-point bending beam test and determined tensile strength, as well as fracture energy density determined by HMA fracture mechanical framework at the first [17]. Saha et al. [18] investigated fracture damage of conventional dense and modified asphalt mixtures using the SCB test. Due to the several merits in terms of specimen preparation and testing, such as repeatability, reproducibility, consistency, and simplicity, the SCB test received a growing interest by the research community to characterize fracture properties of asphalt mixtures [19]. Wang et al. [20] performed the SCB test to assess the low-temperature anticracking performance of crumb rubber modified asphalt mixtures, and found that the flexural tensile strength and fracture energy density increased initially, then reached a peak point, and finally decreased with the increase of rubber dosage. So far, the SCB test specifically for steel slag asphalt mixtures is still lacking, and there are fewer studies using steel slag rubber asphalt mixtures.

The main purpose of this paper was to conduct the uniaxial penetration test and SCB test to evaluate high-temperature deformation and low-temperature fracture behavior of SSRAM, which is also aimed at taking forward this research area for implementation in expressway pavement designs. This study provides technical support and theoretical basis for the application of steel slag to road surface layer. 


\section{Raw Materials and Preparation}

\subsection{Raw Materials and Preparation}

Steel slag and basalt are used as coarse aggregate (The particle size is greater than $4.75 \mathrm{~mm}$ ) in this paper. The immersion expansion rate of the steel slag meets the requirements of the specification. And the material composition design of steel slag and basalt is adapted from previous studies [9]. The appearance of steel slag and basalt is shown in Fig. 1.

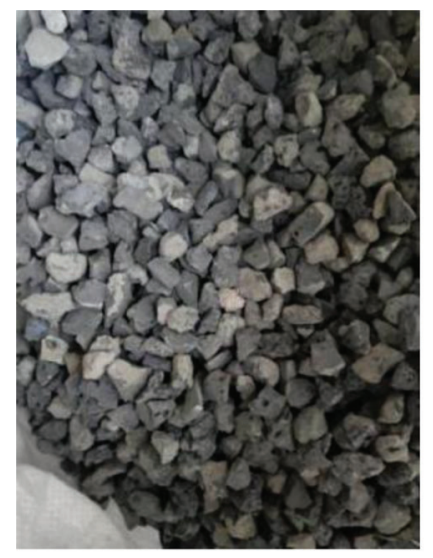

(a)

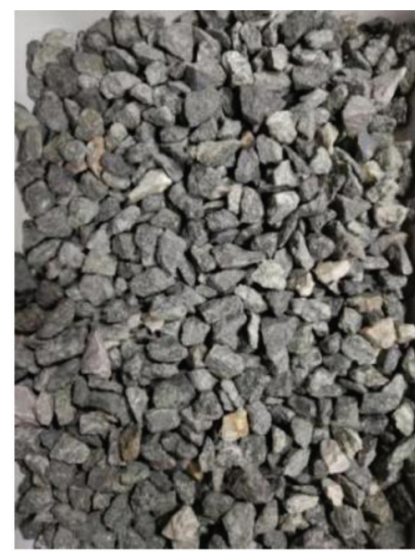

(b)

Figure 1: The appearance of steel slag and basalt: (a) Steel slag (b) Basalt

The AC-13C gradation was adopted to prepare SSRAM (Fig. 2), and the optimal asphalt-aggregation ratio for SSRAM was determined by the Marshall compaction test [7]. The results are shown in Tab. 1.

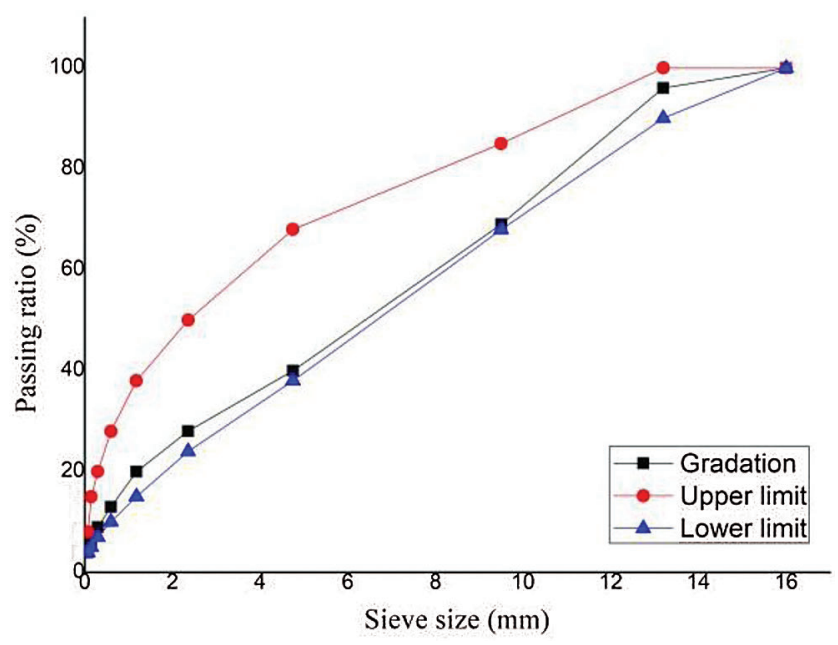

Figure 2: Gradations of SSRAM 
Table 1: Optimal asphalt-aggregation ratios of SSRAM. Adapted with permission from [9]. Copyright (C) 2021, Journal of Renewable Materials

\begin{tabular}{llllllll}
\hline $\begin{array}{l}\text { Content of } \\
\text { steel slag }(\%)\end{array}$ & $\begin{array}{l}\text { Gross volume } \\
\text { density }\left(\mathrm{g} / \mathrm{cm}^{3}\right)\end{array}$ & $\begin{array}{l}\text { VV } \\
(\%)\end{array}$ & $\begin{array}{l}\text { VFA } \\
(\%)\end{array}$ & $\begin{array}{l}\text { VMA } \\
(\%)\end{array}$ & $\begin{array}{l}\text { Stability } \\
(\mathrm{kN})\end{array}$ & $\begin{array}{l}\text { Flow value } \\
(0.1 \mathrm{~mm})\end{array}$ & $\begin{array}{l}\text { Asphalt-aggregation } \\
\text { ratio }(\%)\end{array}$ \\
\hline 0 & 2.564 & 3.9 & 74.3 & 15.2 & 9.4 & 30 & 4.95 \\
20 & 2.582 & 3.9 & 74.8 & 15.5 & 9.6 & 28 & 5.15 \\
40 & 2.617 & 3.8 & 75.6 & 15.6 & 9.5 & 27 & 5.34 \\
60 & 2.633 & 3.9 & 75.3 & 15.8 & 9.5 & 29 & 5.48 \\
80 & 2.641 & 3.8 & 76.2 & 16.0 & 9.2 & 31 & 5.57 \\
100 & 2.646 & 3.8 & 76.4 & 16.1 & 9.1 & 33 & 5.65 \\
\hline
\end{tabular}

The fluorescence micromorphology of rubber asphalt stirred by an impeller agitator for $1 \mathrm{~h}$ is presented in Fig. 3. The rubber asphalt was stood for swelling at $170-180^{\circ} \mathrm{C}$ for $1 \mathrm{~h}$. In this study, the original appearance of broken rubber was retained in the rubber asphalt to strengthen the bonding effect between rubber asphalt and porous steel slag [21,22].

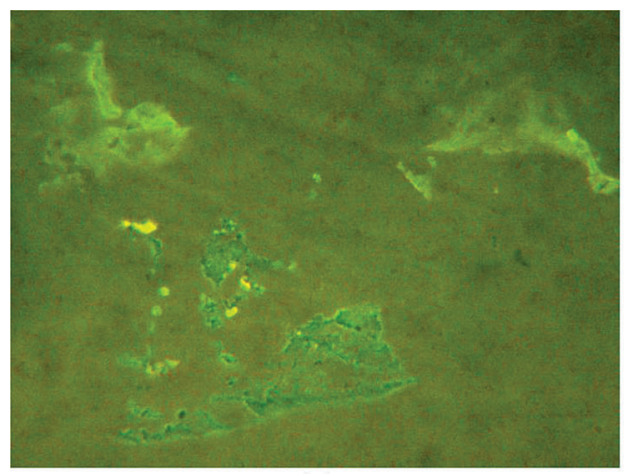

(a)

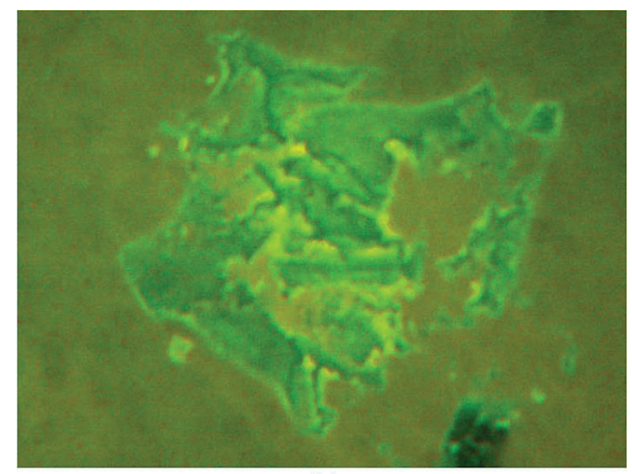

(b)

Figure 3: Fluorescence micromorphology of rubber asphalt after preservation for one hour: (a) Irregular morphology (b) Agglomeration (The number in this figure indicates the diameter of rubber particles, ranging from 0.0375 to $0.9245 \mathrm{~mm}$ )

\section{Experimental Procedure}

\subsection{Uniaxial Penetration Test}

Following the standard test method in specification JTG D50-2017, the test temperature and loading rate were $60^{\circ} \mathrm{C}$ and $1 \mathrm{~mm} / \mathrm{min}$, respectively. Following the standard test method T 0702-2011, the asphalt mixture specimens with different steel slag contents were prepared.

\subsection{SCB Test}

The SCB test is used to characterize the fracture resistance of asphalt mixtures based on a fracture mechanics theory. For linear elastic materials, $\mathrm{K}$ is a function of the applied stress and geometric factor of the specimen, which increases as the applied stress increases and reaches a critical value $\left(\mathrm{K}_{1 \mathrm{C}}\right)$ when the failure occurs. Besides, $\mathrm{K}_{1 \mathrm{C}}$ also termed fracture toughness is an intrinsic property of the material, which helps explain the fracture resistance property of the material [23]. Following the standard test method $\mathrm{T}$ 0702-2011, large marshall specimens were prepared in this study. Then splitting specimens for SCB test 
with conditions of the ratio of the support span to the specimen diameter being 0.8 . The specimens were $150 \mathrm{~mm}$ in diameter and about $20 \mathrm{~mm}$ thick. The length of support span was $120 \mathrm{~mm}$. The test temperature and loading rates were $-10^{\circ} \mathrm{C}$ and $10 \mathrm{~mm} / \mathrm{min}$, respectively. In this test, semi-circular samples with two notch depths of 5 and $10 \mathrm{~mm}$ were used. Finally, a laser displacement meter was placed on the crack position to measure the displacement-time curves of the crack. A semi-circular specimen was preparing to test and others were loaded specimens, which showed in Fig. 4.

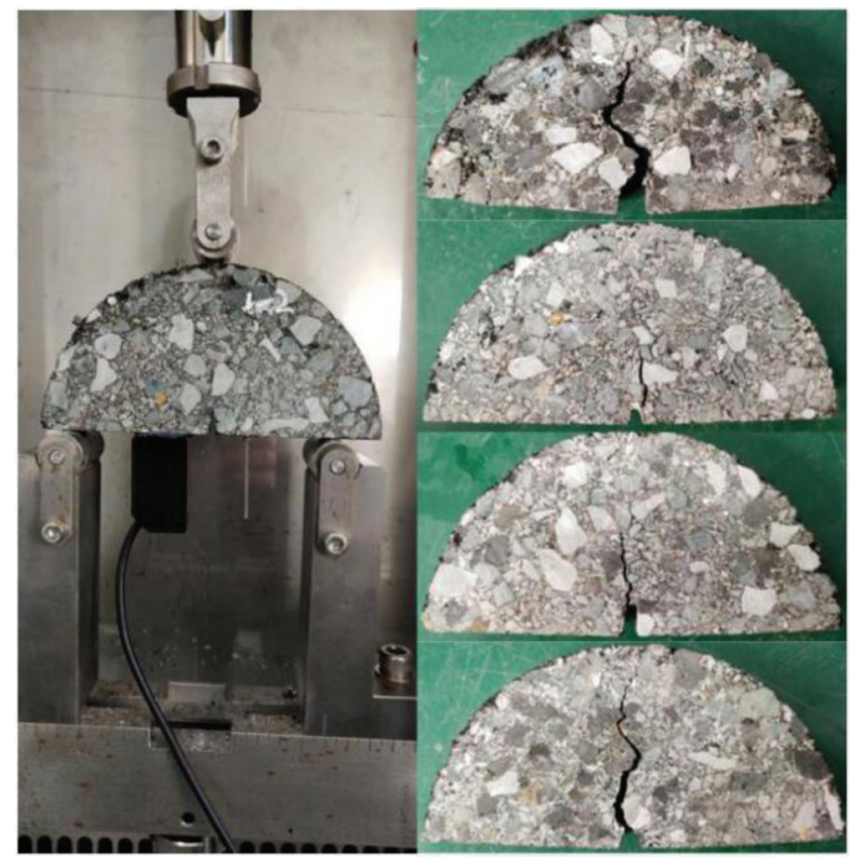

Figure 4: Set-up of semi-circular bend test and loaded specimens

\section{Results and Discussion}

\subsection{Uniaxial Penetration Strength}

Following the specification JTG D50-2017, the uniaxial penetration strength of the asphalt mixture should meet the requirements of Eq. (1) when the base was stabilized by the inorganic binders.

$R_{T S} \geq\left(\frac{0.31 \times \lg N_{e 5}-0.68}{\lg \left[R_{a}\right]-13.1 \times \lg T_{d}-\lg \psi_{s}+2.50}\right)^{1.86}$

where $\left[\mathrm{R}_{\mathrm{a}}\right]$ is the allowable permanent deformation of asphalt mixture, $\mathrm{N}_{\mathrm{e} 5}$ is cumulative equivalent single axle loads for design lane, $\mathrm{T}_{\mathrm{d}}$ is design temperature, $\psi_{s}$ is pavement structural coefficient and $\psi_{s}=\left(0.52 h_{a}^{-0.003}-317.59 h_{b}^{-1.32}\right) E_{b}^{0.1}, \mathrm{~h}_{\mathrm{a}}$ is the thickness of asphalt mixture layer, $\mathrm{h}_{\mathrm{b}}$ represents the stabilizing layer thickness of inorganic binder, $\mathrm{E}_{\mathrm{b}}$ is the modulus of the stable layer of inorganic binder, $\mathrm{R}_{\mathrm{TS}}$ is the minimum allowable permanent deformation. $\mathrm{R}_{\mathrm{TS}}$ is a calculated value based on engineering parameters and specifications, which is compared with the failure deformation measured by uniaxial penetration test and rutting deformation. The proposed parameters $\mathrm{R}_{\mathrm{TS}}$ put forward further requirements on the high temperature performance of the steel slag asphalt mixture surface layer, which is rarely considered in the usual asphalt pavement design process. The specification (JTG D50-2017) requires that the permanent deformation of asphalt pavement structure in expressway is less than $15 \mathrm{~mm}$. 
Tab. 2 presents the uniaxial penetration test results, which show that there are elastic stage and yield stage in the test process of SSRAM. The deformation in the elastic stage accounts for $25.5 \% \sim 41.5 \%$ of the total deformation. The uniaxial penetration strength of SSRAM increases first and then decreases with the increase of steel slag content, while the total deformation of the specimen increases monotonically.

Table 2: Results of the uniaxial penetration test

\begin{tabular}{lllllll}
\hline \multirow{2}{*}{$\begin{array}{l}\text { Content of } \\
\text { steel slag }(\%)\end{array}$} & \multicolumn{2}{c}{ The elastic stage } & & \multicolumn{2}{c}{ The yield stage } & \multicolumn{2}{l}{$\begin{array}{l}\text { Uniaxial penetration } \\
\text { strength }(\mathrm{MPa})\end{array}$} \\
\cline { 2 - 3 } \cline { 5 - 6 } & Stress $(\mathrm{kN})$ & Displace $(\mathrm{mm})$ & & Stress $(\mathrm{kN})$ & Displace $(\mathrm{mm})$ & \\
\hline 0 & 2.47 & 0.53 & 5.21 & 1.40 & 1.71 \\
20 & 2.54 & 0.61 & 5.36 & 1.47 & 2.13 \\
40 & 2.67 & 0.72 & 5.85 & 1.76 & 1.96 \\
60 & 3.13 & 0.69 & 6.58 & 2.40 & 1.74 \\
80 & 2.41 & 0.64 & 5.13 & 2.51 & 1.49 \\
100 & 2.12 & 1.14 & 4.55 & 3.47 & 1.17 \\
\hline
\end{tabular}

\subsection{Analysis of High-Temperature Performance}

According to the specification, the penetration strength of the generally modified asphalt mixture is 0.7 1.2 MPa. The uniaxial penetration strength of SSRAM is higher than that. Based on the design parameters of the expressway in Hebei Province and the penetration strength of SSRAM, the minimum allowable permanent deformation $\left(\mathrm{R}_{\mathrm{TS}-\mathrm{min}}\right)$ of the SSRAM surface layer can be obtained by Eq. (1). The results are shown in Tab. 3.

Table 3: Comparison of $\mathrm{R}_{\mathrm{TS}}$ and failure deformation

\begin{tabular}{llll}
\hline $\begin{array}{l}\text { Content of } \\
\text { steel slag }(\%)\end{array}$ & $\begin{array}{l}\mathrm{R}_{\mathrm{TS}-\mathrm{min}} \\
(\mathrm{mm})\end{array}$ & $\begin{array}{l}\text { Total rutting } \\
\text { depth }(\mathrm{mm})\end{array}$ & $\begin{array}{l}\text { Failure deformation } \\
(\mathrm{mm})\end{array}$ \\
\hline 0 & 2.83 & 1.988 & 1.40 \\
20 & 2.63 & 2.061 & 1.47 \\
40 & 2.67 & 2.321 & 1.76 \\
60 & 2.83 & 2.728 & 2.40 \\
80 & 3.01 & 3.076 & 2.51 \\
100 & 3.26 & 2.969 & 3.47 \\
\hline
\end{tabular}

The data in Tab. 3 showed that the total rutting depth and failure deformation of the SSRAM surface layer was likely to be higher than the allowable permanent deformation, as the steel slag content exceeded $60 \%$. Previous studies demonstrated that the dynamic stability of SSRAM with different contents can meet the specification requirement. For asphalt pavement, rutting and deformation usually occur in the surface layer and middle layer and deformation accounts for $15 \%$ 20\% of the pavement structure, which requires SSRAM surface layer mixture to perform well in high temperature. The Chinese asphalt pavement design code requires that the permanent deformation of the expressway surface should be less than $15 \mathrm{~mm}$. The total rutting depth and failure deformation of SSRAM with 80 steel slag content is higher than $\mathrm{R}_{\mathrm{TS}-\mathrm{min}}$. Consequently, the rutting depth and failure deformation of SSRAM should be 
controlled within $3 \mathrm{~mm}$ to meet the requirements of the expressway, and the steel slag content of SSRAM should be less than $60 \%$.

\subsection{Low Temperature Cracking Index}

To make SSRAM meet the requirements of pavement structure design in some seasonal permafrost areas, the low temperature cracking index (CI) should be calculated by Eq. (2).

$C I=1.95 \times 10^{-3} S_{t} \lg b-0.075\left(T+0.07 h_{a}\right) \lg S_{t}+0.15$

where $\mathrm{T}$ is the mean of the lowest temperature for 10 consecutive years, $\mathrm{S}_{\mathrm{t}}$ is the creep stiffness of asphalt BBR test at particular temperature range required by the specification when loading $180 \mathrm{~s}$, ha is the thickness of asphalt mixture layer, $b$ is the subgrade type parameter.

Referring to the results of creep stiffness in the BBR test of rubber asphalt [24,25], the low temperature cracking index of the SSRAM surface layer was calculated as 1.37 based on the design parameters of the Chinese expressway, which was less than the value required by the specification.

\subsection{Fundamental Fracture Failure Properties}

Judging from the low-temperature stress-displacement curve, it is in line with elastoplastic fracture, which should be analyzed from the theories of elastoplastic fracture mechanics. The plane stress yield model proposed by Dugdale, which is similar to the Barenblatt model, assuming that the yield of the material is limited to a narrow area directly in front of the crack tip. In the fractured plastic zone, the cohesive force acts on the surface of the expanding crack to inhibit crack opening and crack growth. This distance can be regarded as the crack plastic zone (Fig. 5). The average plastic growth strain can be calculated by Eq. (3).

$\bar{\varepsilon}_{\text {plastic }}=\frac{\delta}{h}$

where $\delta$ represents the crack opening distance and $h$ represents the thickness of the SCB specimen.

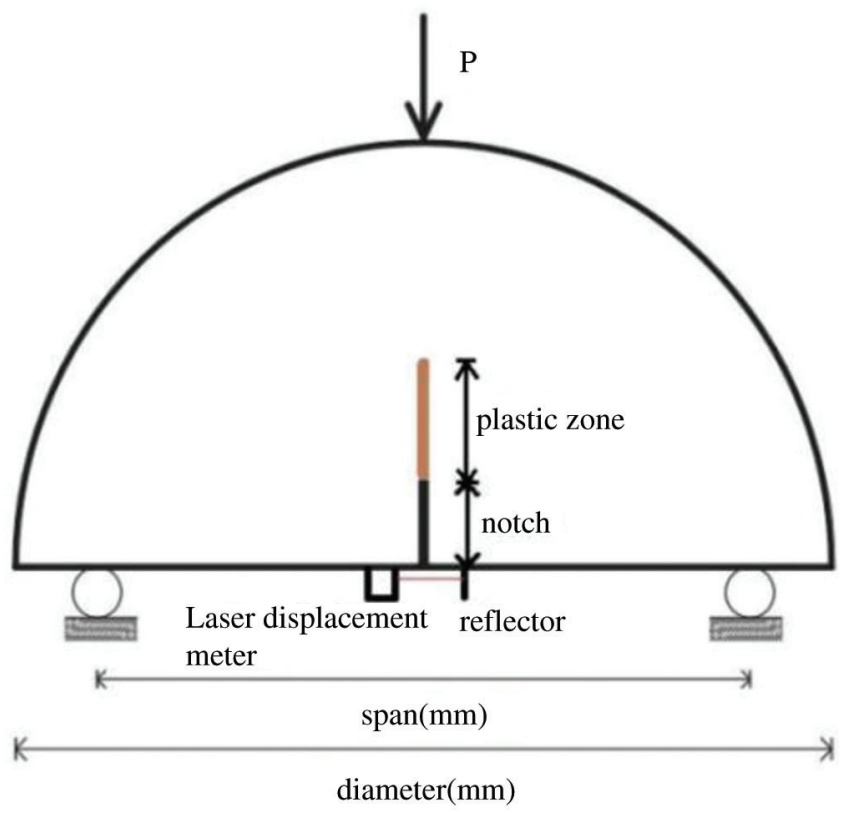

Figure 5: Diagram of the plastic zone in-plane stress yield process 
The opening displacement of the crack tip can be solved from the stress-displacement curve and $\mathbf{J}$ integral (Eqs. (4)-(5)).

$J=\int_{0}^{\delta_{t}} \sigma(\delta) d \delta=h \int_{0}^{\delta_{t}} \sigma\left(\bar{\varepsilon}_{\text {plastic }}\right) d \bar{\varepsilon}_{\text {plastic }}$

$J=\frac{K_{1}^{2}}{E}=h \int_{0}^{\frac{\delta_{t}}{h}} \sigma\left(\bar{\varepsilon}_{\text {plastic }}\right) d \bar{\varepsilon}_{\text {plastic }}$

When the asphalt mixture yields incompletely plastic in the fracture process, the stress-strain curve is shown in Fig. 6, thereby the crack opening displacement can be calculated through Eqs. (6)-(10).

$\sigma\left(\bar{\varepsilon}_{\text {plastic }}\right)=\sigma_{0}+E_{\text {tan }} \bar{\varepsilon}_{\text {plastic }}$

$$
\delta_{t}=\frac{\sigma_{0} h}{E_{\tan }}\left[\left(1+\frac{2 E_{\tan } J}{h \sigma_{0}^{2}}\right)-1\right]
$$

$\left.\delta_{t}=\frac{\sigma_{0} h}{E_{\tan }}\left[\left(1+\frac{2 E_{\tan }}{E} \times \frac{K_{1}^{2}}{h \sigma_{0}^{2}}\right)-1\right]\right\}$

$\sigma_{\max }=\frac{4.263 P_{\max }}{D b}$

$K_{1 c}=\sigma_{\max } \sqrt{\pi a} f\left(\frac{a}{W}\right)$

$f\left(\frac{a}{W}\right)=-0.623+29.29\left(\frac{a}{W}\right)-171.2\left(\frac{a}{W}\right)^{2}+457.1\left(\frac{a}{W}\right)^{3}-561.2\left(\frac{a}{W}\right)^{4}+265.54\left(\frac{a}{W}\right)^{5}$

where $\sigma_{\max }$ is the maximum stress, $F_{\max }$ is the maximum load, $\mathrm{K}_{1 \mathrm{c}}$ is the fracture toughness, a is the initial notch depth and $\mathrm{W}$ is the specimen's radius.

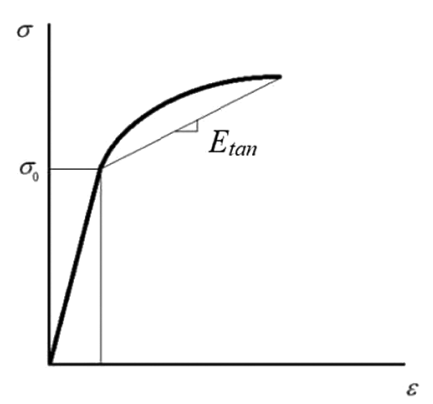

Figure 6: Stress-strain curve of incomplete plastic yield

Combined with the SCB test results and Eqs. (4)-(10), two key parameters $\mathrm{J}$ integral and $\mathrm{K}_{1 \mathrm{c}}$ affecting the low-temperature performance of asphalt mixture can be calculated. Fig. 7 shows the results of the SCB test. The red and black lines represent the crack Displacement-Time curve, and the other three lines represent the Load-Time curve of SSRAM. The Load-CMOD curves can be obtained after data merge processing. 

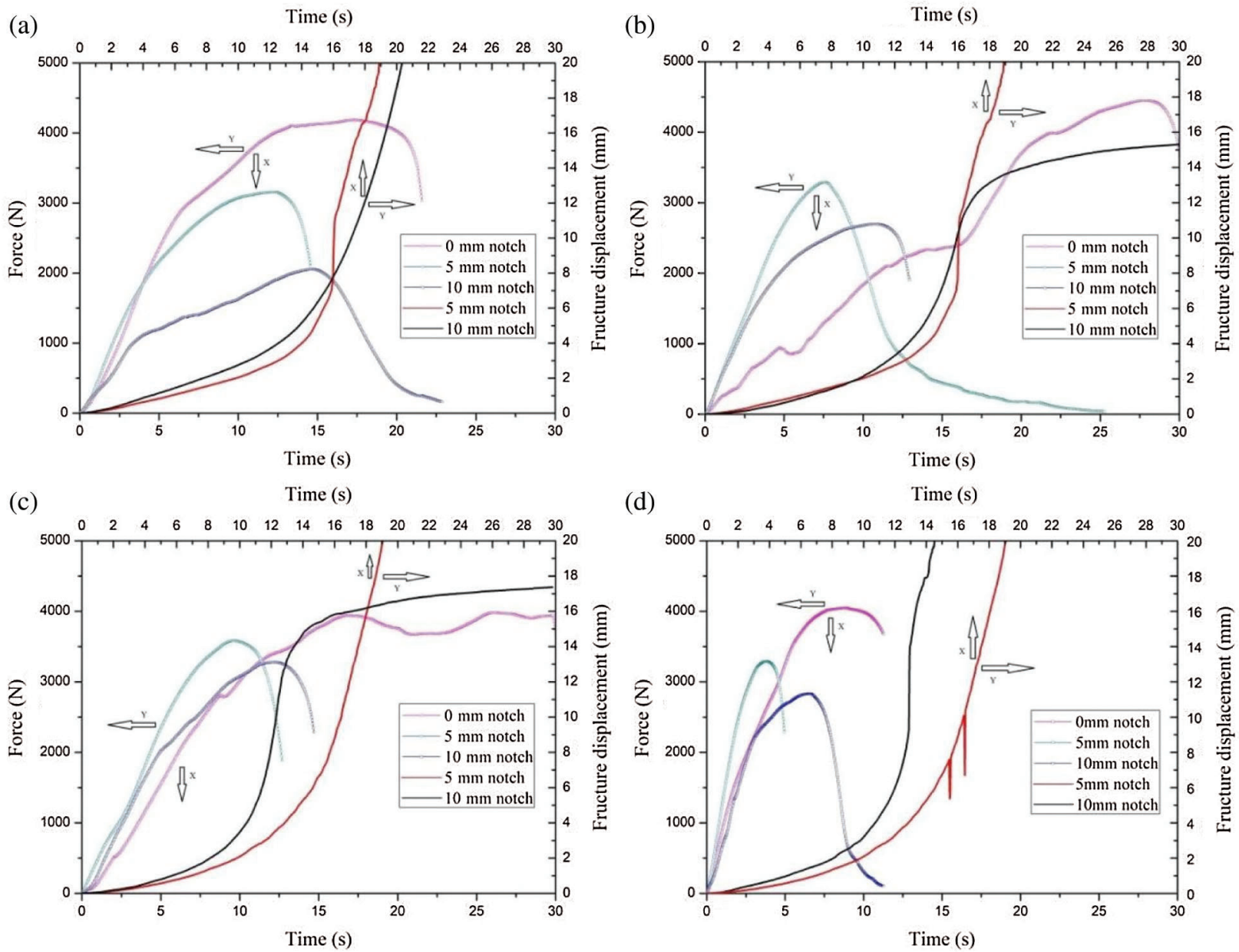

(d)
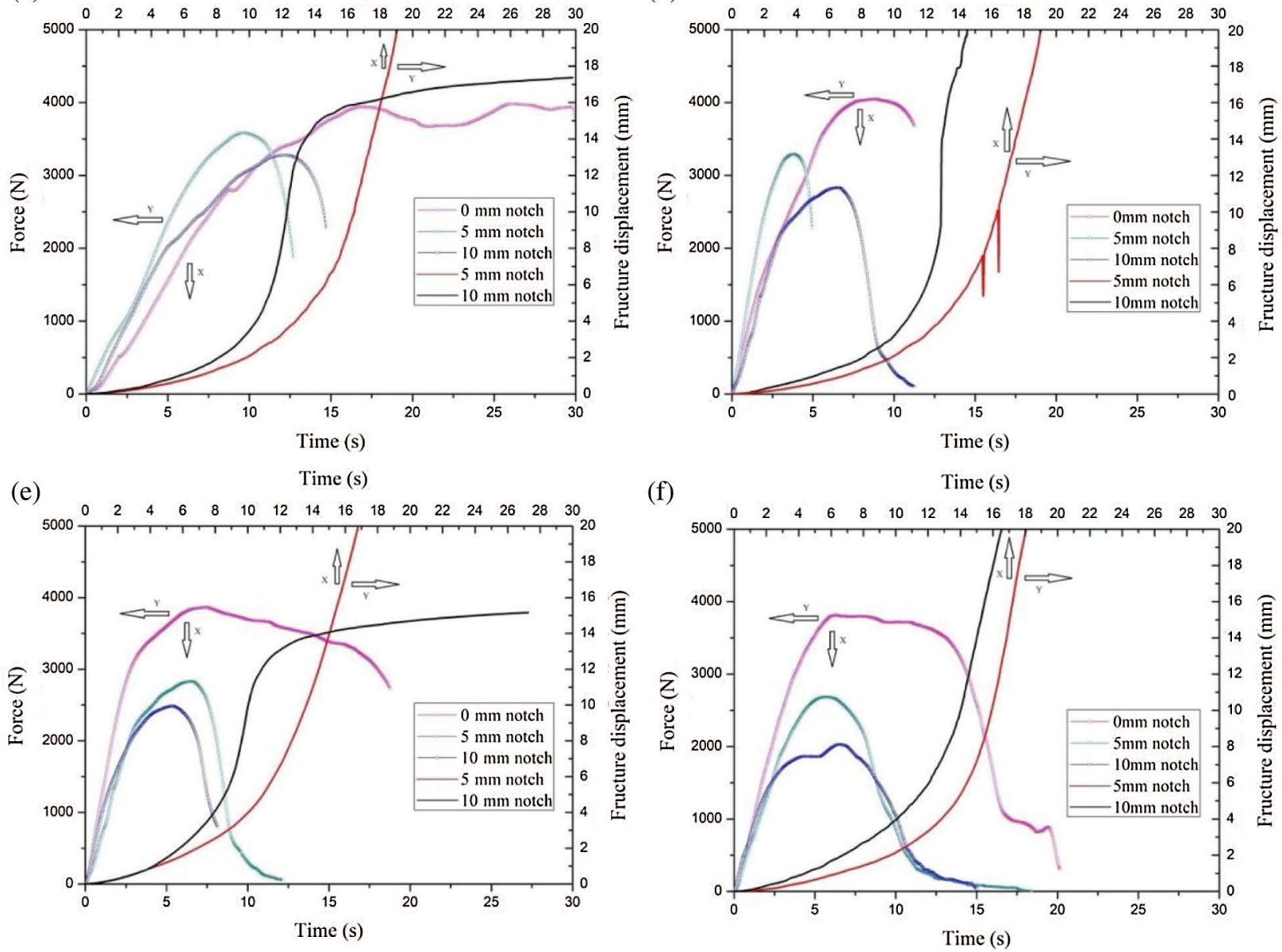

Figure 7: Displacement-time and load-time curves of SSRAM: (a) $0 \%$ (b) $20 \%$ (c) $40 \%$ (d) $60 \%$ (e) $80 \%$ and (f) $100 \%$ (The black and red curves in this figure indicate the fructure displacements-time curves of the crack, and the other three curves indicate the stress-time curves of the SCB specimen) 
The stress peak of SSRAM at different depth notches is shown in Tab. 4, which all tested at $-10^{\circ} \mathrm{C}$. With the increase of notch depth in $40 \%$ SSRAM, the degradation rate of stress peak is $20.04 \%$. Meanwhile, it can be found that the stress peak of SSRAM with $0 \%$ and $100 \%$ steel slag content decreased by $50.91 \%$ and $46.82 \%$, respectively. The reason may be that there is a material optimum ratio of the mixture composed of porous steel slag and basalt. The fracture performance will increase compared with that of the mixture composed of single material when the content of steel slag and basalt reaches the optimum ratio.

Table 4: Stress peak of SSRAM at different depth notches

\begin{tabular}{|c|c|c|c|c|c|c|c|c|}
\hline \multirow{2}{*}{$\begin{array}{l}\text { Content of } \\
\text { steel slag }(\%)\end{array}$} & \multicolumn{2}{|c|}{$0 \mathrm{~mm}$ notch } & \multicolumn{3}{|c|}{$5 \mathrm{~mm}$ notch } & \multicolumn{3}{|c|}{$10 \mathrm{~mm}$ notch } \\
\hline & $\begin{array}{l}\text { Force } \\
(\mathrm{N})\end{array}$ & $\begin{array}{l}\text { Stress } \\
(\mathrm{MPa})\end{array}$ & $\begin{array}{l}\text { Force } \\
(\mathrm{N})\end{array}$ & $\begin{array}{l}\text { Stress } \\
(\mathrm{MPa})\end{array}$ & $\begin{array}{l}\text { Decrease } \\
(\%)\end{array}$ & $\begin{array}{l}\text { Force } \\
(\mathrm{N})\end{array}$ & $\begin{array}{l}\text { Stress } \\
(\mathrm{MPa})\end{array}$ & $\begin{array}{l}\text { Decrease } \\
(\%)\end{array}$ \\
\hline 0 & 4186.50 & 6.07 & 3157.16 & 4.58 & 24.59 & 2055.30 & 2.98 & 50.91 \\
\hline 20 & 4447.39 & 6.52 & 3286.31 & 4.81 & 26.11 & 2697.61 & 3.95 & 39.34 \\
\hline 40 & 4100.64 & 5.95 & 3582.71 & 5.19 & 12.63 & 3278.77 & 4.75 & 20.04 \\
\hline 60 & 4048.08 & 5.87 & 3289.41 & 4.77 & 18.74 & 2830.54 & 4.10 & 30.08 \\
\hline 80 & 3864.98 & 5.66 & 2830.54 & 4.15 & 26.76 & 2486.95 & 3.64 & 35.65 \\
\hline 100 & 3813.59 & 5.53 & 2684.70 & 3.89 & 29.60 & 2028.20 & 2.94 & 46.82 \\
\hline
\end{tabular}

\subsubsection{Fracture Toughness}

Fracture toughness can characterize the strength of the stress field at the crack tip. The fracture toughness of SSRAM can be calculated by Eqs. (8)-(10). The calculation results related to the fracture toughness of SSRAM are shown in Tab. 5.

Table 5: Critical fracture toughness of SSRAM

\begin{tabular}{lllll}
\hline \multirow{2}{*}{$\begin{array}{l}\text { Content of } \\
\text { steel slag }(\%)\end{array}$} & \multicolumn{4}{c}{$\mathrm{K}_{1 \mathrm{C}}\left(\mathrm{MPa} \cdot \mathrm{m}^{1 / 2}\right)$} \\
\cline { 2 - 5 } & $5 \mathrm{~mm}$ notch & $\mathrm{COV}(\%)$ & $10 \mathrm{~mm}$ notch & $\mathrm{COV}(\%)$ \\
\hline 0 & 0.3979 & 7.3 & 0.6107 & 4.5 \\
20 & 0.4184 & 8.1 & 0.8098 & 5.8 \\
40 & 0.4515 & 5.8 & 0.9742 & 4.6 \\
60 & 0.4146 & 3.9 & 0.8410 & 2.2 \\
80 & 0.3604 & 5.2 & 0.7466 & 5.4 \\
100 & 0.3383 & 4.7 & 0.6026 & 3.7 \\
\hline
\end{tabular}

In the SCB test, the covariance value of the test results of each group was less than $10 \%$, thereby the test results were considered stable. Fig. 8 shows typical specimens after the SCB test. Compared with the notch depth of 0,5 , and $10 \mathrm{~mm}$, the peak stress decreases with the increase of notch depth. However, the fracture toughness of the $5 \mathrm{~mm}$ specimen was less than that of the $10 \mathrm{~mm}$ specimen. Eq. (9) indicated that fracture toughness is not only proportional to fracture stress, but also proportional to the square root of notch depth. Meanwhile, the test results proved that the fracture toughness of the specimen is not only affected by the fracture stress, but the depth of the crack has a significant effect on the fracture toughness of the SSRAM 
surface layer. Studies have proved that the fracture toughness of specimens with 10,15 , and $20 \mathrm{~mm}$ notch decreases with the increase of crack depth. However, it is not accurate enough to analyze the test results only from the perspective of fracture toughness. For the cracking resistance of asphalt mixture, other parameters should be considered.

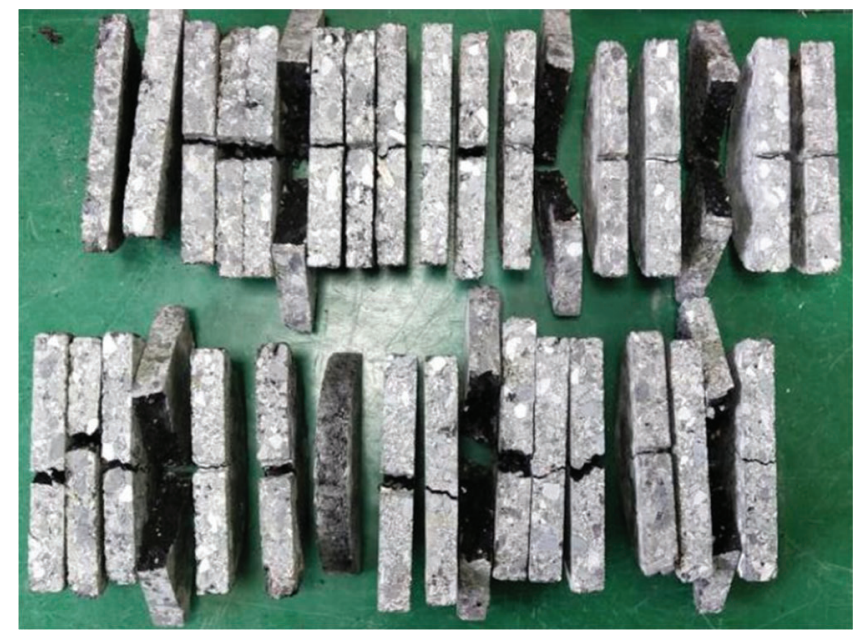

Figure 8: Part of the specimen after SCB test

\subsubsection{Fracture Energy}

Fracture energy means the energy absorbed by the specimen during the fracture process. Within a certain range, the higher the fracture energy of the asphalt mixture, the better the crack resistance of the mixture.

Tab. 6 shows the $\mathrm{J}_{1 \mathrm{C}}$ values of SSRAM, each group's covariance value of test results is less than $10 \%$, and the test results show that the fracture energy of the mixture gradually decreases with the increase of the crack depth of the asphalt mixture. The aggrandization of steel slag content leads to the decrease of $\mathrm{J}_{1 \mathrm{C}}$ values. However, it proved that $40 \%$ steel slag has the best low-temperature fracture performance based on $\mathrm{K}_{1 \mathrm{C}}$ and fracture stress peak. Evaluation indicators that affect the low-temperature performance of SSRAM need to be discussed from multiple perspectives to guide engineering applications more effectively.

Table 6: $\mathrm{J}_{1 \mathrm{C}}$ values of SSRAM

\begin{tabular}{|c|c|c|c|c|}
\hline \multirow{2}{*}{$\begin{array}{l}\text { Content of } \\
\text { steel slag (\%) }\end{array}$} & \multicolumn{2}{|c|}{ Fracture energy $(\mathrm{J})$} & \multirow[t]{2}{*}{$\operatorname{COV}(\%)$} & \multirow[t]{2}{*}{$\mathrm{J}_{1 \mathrm{C}}\left(\mathrm{J} / \mathrm{mm}^{2}\right)$} \\
\hline & $5 \mathrm{~mm}$ notch & $10 \mathrm{~mm}$ notch & & \\
\hline 0 & 8.94 & 7.33 & 4.36 & 0.0805 \\
\hline 20 & 6.95 & 5.39 & 7.84 & 0.0780 \\
\hline 40 & 7.89 & 6.51 & 8.89 & 0.0697 \\
\hline 60 & 7.34 & 6.15 & 8.36 & 0.0598 \\
\hline 80 & 5.87 & 4.64 & 6.13 & 0.0615 \\
\hline 100 & 5.62 & 4.49 & 4.45 & 0.0565 \\
\hline
\end{tabular}




\subsubsection{Crack Propagation Velocity and Fitted Equation}

During the SCB test, a laser displacement sensor was installed to record the displacement-time curve of the crack. Through the fitted curves, the crack propagation velocity more intuitively can be calculated. Velocity, acceleration, fracture stress peak, $J_{1 \mathrm{C}}$ values, and fracture toughness $\mathrm{K}_{1 \mathrm{C}}$ can be more comprehensive to evaluate the low-temperature crack resistance of SSRAM. The crack's DisplacementTime curves are shown in Fig. 7.

The crack propagation velocity and acceleration continuously increased before the fracture stress reached the peak. It can be considered that the crack propagation velocity conforms to the exponential function image. Then, a parameter equation applicable to the crack propagation velocity of SSRAM was proposed (Eq. (11)). The crack propagation velocity can be evaluated by the two parameters A, B. However, these two parameters were likely to be affected temperature in asphalt mixtures. To explore the variation rules of parameters $\mathrm{A}$ and $\mathrm{B}$, a large number of experiments should be conducted. MATLAB was used to fit the Deformation-Time curve of the crack, as shown in Fig. 9.

$\delta(t)=A e^{B t}, v(t)=\frac{d \delta(t)}{d t}=A B e^{B t} . A>0, \quad B>0, \quad t>0$

Eq. (12) was the fitted equation of crack propagation velocity.

$\left\{\begin{array}{l}\delta_{0 \%-5 m m}(t)=0.08575 e^{0.2919 t}, \text { Adjusted }-r^{2}=0.9736 \\ \delta_{0 \%-10 \mathrm{~mm}}(t)=0.3158 e^{0.2032 t}, \text { Adjusted }-r^{2}=0.9972 \\ \delta_{20 \%-5 \mathrm{~mm}}(t)=0.0537 e^{0.3222 t}, \text { Adjusted }-r^{2}=0.9653 \\ \delta_{20 \%-10 \mathrm{~mm}}(t)=0.1836 e^{0.2431 t}, \text { Adjusted }-r^{2}=0.9955 \\ \delta_{40 \%-5 \mathrm{~mm}}(t)=0.1423 e^{0.2602 t}, \text { Adjusted }-r^{2}=0.9983 \\ \delta_{40 \%-10 \mathrm{~mm}}(t)=0.0877 e^{0.3753 t}, \text { Adjusted }-r^{2}=0.9871 \\ \delta_{60 \%-5 \mathrm{~mm}}(t)=0.1381 e^{0.2622 t}, \text { Adjusted }-r^{2}=0.9964 \\ \delta_{60 \%-10 \mathrm{~mm}}(t)=0.1782 e^{0.2957 t}, \text { Adjusted }-r^{2}=0.9906 \\ \delta_{80 \%-5 \mathrm{~mm}}(t)=0.3913 e^{0.2361 t}, \text { Adjusted }-r^{2}=0.9986 \\ \delta_{80 \%-10 \mathrm{~mm}}(t)=0.1924 e^{0.3853 t}, \text { Adjusted }-r^{2}=0.9937 \\ \delta_{100 \%-5 \mathrm{~mm}}(t)=0.08242 e^{0.3044 t}, \text { Adjusted }-r^{2}=0.9941 \\ \delta_{100 \%-10 \mathrm{~mm}}(t)=0.2883 e^{0.2571 t}, \text { Adjusted }-r^{2}=0.9962\end{array}\right.$
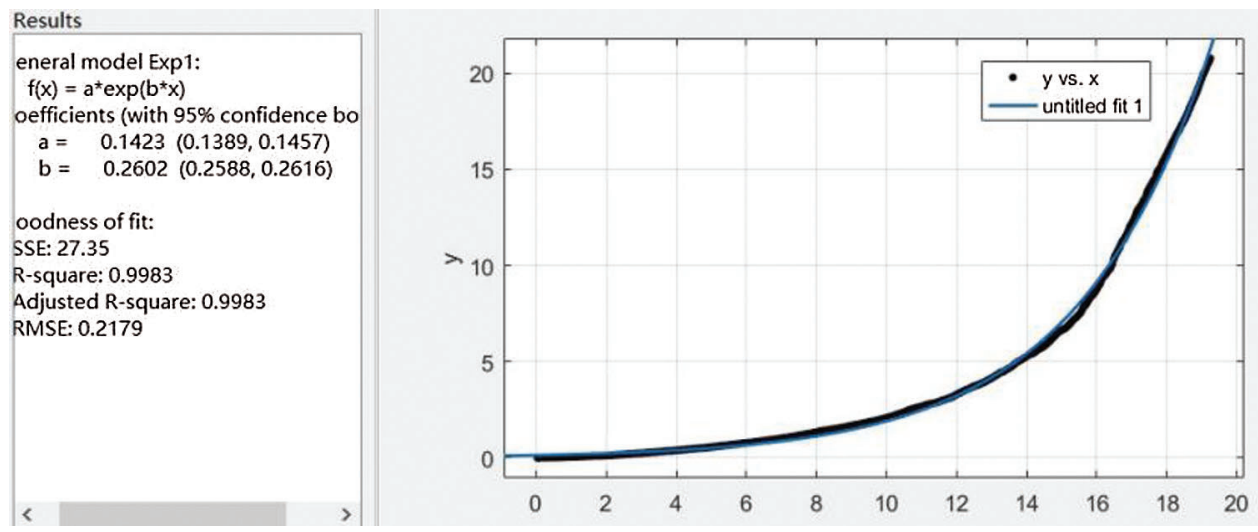

Figure 9: Example of crack displacement-time curve fitting (40\%)

It can be seen from Eq. (12) that the relationship between parameter and variable factor. The influence of steel slag content on parameter A was not significant. However, parameter A increased significantly with the increase of notch depth. When the notch was $5 \mathrm{~mm}$, parameter B increased first and then decreased with the 
increase of steel slag content except for SSRAM specimens with 100\% steel slag content. Meanwhile, parameter B increased first and decreased with the aggrandized steel slag content on the condition that the notch depth was $10 \mathrm{~mm}$. The crack propagation velocity can reflect whether the fracture of asphalt mixture belongs to brittle fracture within a certain range. The greater the crack propagation velocity, the larger the displacement per unit time in the fracture process of asphalt mixture. The acceleration of the crack propagation velocity can be used to determine whether the crack is in the stage of unstable growth. The earlier the unstable crack stage of the mixture occurs, the worse the crack resistance of the specimen. Combined with the theoretical analysis and crack propagation behavior of specimens during the test, it was found that the fracture behavior gradually changes from brittle fracture to plastic fracture with the increase of steel slag content.

The low-temperature fracture properties of the SSRAM surface were evaluated from each of these perspectives, and the SSRAM surface layer with $40 \%$ steel slag content showed a batter application potential in highway construction engineering.

\section{Conclusions}

In this study, the uniaxial penetration test and SCB test were carried out. Following the test results and specification parameters, the uniaxial penetration strength, allowable permanent deformation, low temperature cracking index, fracture toughness, fracture energy and crack propagation velocity of SSRAM with different steel slag contents were calculated. The high-temperature deformation and lowtemperature fracture behavior of SSRAM were analyzed from various aspects. The main conclusions are shown below:

1. The dynamic stability of all specimens meet the specification requirements. The SSRAM with $40 \%$ steel slag content has the highest dynamic stability in rutting test while SSRAM with $20 \%$ steel slag content has the best anti-shearing strength in uniaxial penetration test. Considering the allowable deformation of asphalt mixture, the rutting depth and failure deformation of SSRAM need to be controlled within $3 \mathrm{~mm}$ to meet the requirements of the expressway.

2. The low-temperature cracking index of the SSRAM surface layer is calculated as 1.37 and the SCB test results show that the stress peak degradation rate (specimens with $10 \mathrm{~mm}$ notch are compared with $0 \mathrm{~mm}$ ) of SSRAM with $40 \%$ steel slag content is $20.04 \%$. That means proper steel slag content makes the stress peak degradation rate of SSRAM reaches the lowest value.

3. The fracture toughness of the specimen with $5 \mathrm{~mm}$ notch is less than specimen with $10 \mathrm{~mm}$ notch. The SCB test results proved that the fracture toughness of the specimen is not only affected by the notch depth, but the fracture stress of the crack has a significant effect on the fracture toughness of the SSRAM surface layer.

4. With the increase of the crack depth, the fracture energy of the mixture gradually decreases. The aggrandization of steel slag content leads to the decrease of fracture energy density $\left(\mathrm{J}_{1 \mathrm{C}}\right)$, it may be one of the main factors preventing SSRAM with high steel slag content from being used extensively in asphalt pavement.

5. The crack propagation velocity and acceleration continuously increased before the fracture stress reached the peak. It can be considered that the crack propagation velocity conforms to the exponential function. Then, a parameter equation applicable to the crack propagation velocity of SSRAM was proposed in this study. Considering the high-temperature deformation resistance and low-temperature fracture property, the SSRAM surface layer with $40 \%$ steel slag content showed a batter application potential. 
Funding Statement: This research was funded by the Department of Transportation of Hebei Province (Grant No. TH1-202019). In addition, the authors would like to thank the reviewers of this paper for their ever-present support and valuable advice.

Conflicts of Interest: The authors declare that they have no conflicts of interest to report regarding the present study.

\section{References}

1. Tsakiridis, P. E., Papadimitriou, G. D., Tsivilis, S., Koroneos, C. (2008). Utilization of steel slag for Portland cement clinker production. Journal of Hazardous Materials, 152(2), 805-811. DOI 10.1016/j. jhazmat.2007.07.093.

2. Shi, C. J. (2005). Steel slag-its production, processing, characteristics, and cementitious properties. Cheminform, 36, 230-236. DOI 10.1002/chin.200522249.

3. Ziaee, S. A., Behnia, K. (2020). Evaluating the effect of electric arc furnace steel slag on dynamic and static mechanical behavior of warm mix asphalt mixtures. Journal of Cleaner Production, 274(8), 123092. DOI 10.1016/j.jclepro.2020.123092.

4. Ren, Y., Chen, M., Yang, T., Wu, S., Wang, K. (2021). Effect of steel slag aggregate on pavement and flameretardant performance of warm-mixed flame-retardant asphalt concrete. Materials, 14(3), 635. DOI 10.3390/ ma14030635.

5. Asi, I. M., Qasrawi, H. Y., Shalabi, F. I. (2007). Use of steel slag aggregate in asphalt concrete mixes. Canadian Journal of Civil Engineering, 34(8), 902-911. DOI 10.1139/107-025.

6. Maslehuddin, M., Sharif, A. M., Shameem, M., Ibrahim, M., Barry, M. S. (2003). Comparison of properties of steel slag and crushed limestone aggregate concretes. Construction and Building Materials, 17(2), 105-112. DOI 10.1016/S0950-0618(02)00095-8.

7. Ahmedzade, P., Sengoz, B. (2009). Evaluation of steel slag coarse aggregate in hot mix asphalt concrete. Journal of Hazardous Materials, 165(1-3), 300-305. DOI 10.1016/j.jhazmat.2008.09.105.

8. Pasetto, M., Baldo, N. (2012). Fatigue behavior characterization of bituminous mixtures made with reclaimed asphalt pavement and steel slag. Procedia-Social and Behavioral Sciences, 53, 297-306. DOI 10.1016/j. sbspro.2012.09.882.

9. Shu, Z., Wu, J., Li, S., Zhang, B., Yang, J. (2021). Road performance, thermal conductivity, and temperature distribution of steel slag rubber asphalt surface layer. Journal of Renewable Materials, 9(2), 365-380. DOI 10.32604/jrm.2021.014379.

10. Tayfur, S., Ozen, H., Aksoy, A. (2007). Investigation of rutting performance of asphalt mixtures containing polymer modifiers. Construction and Building Materials, 21(2), 328-337. DOI 10.1016/j. conbuildmat.2005.08.014.

11. Witczak, M. W., Kaloush, K., Von Quintus, H. (2002). Pursuit of the simple performance test for asphalt mixture rutting. Asphalt Paving Technology: Association of Asphalt Paving Technologists-Proceedings of the Technical Sessions, pp. 671-691. Colorado Springs, Colorado.

12. Liu, W., Liu, X., Wang, Z., Zhou, Z. (2020). New asphalt concrete rutting resistance evaluation method based on repeated-load test. Journal of Materials in Civil Engineering, 32(2), 4019351. DOI 10.1061/(ASCE)MT.19435533.0002996.

13. Chen, X., Huang, B., Xu, Z. (2006). Uniaxial penetration testing for shear resistance of hot-mix asphalt mixtures. Transportation Research Record, 1970(1), 116-125. DOI 10.1177/0361198106197000112.

14. Su, K., Sun, L. J., Hachiya, Y. (2008). A new method for predicting rutting in asphalt pavements employing static uniaxial penetration test. International Journal of Pavement Research and Technology, 1, 24. DOI 10.6135/ijprt. org.tw/2008.1(1).24. 
15. Das, P. K., Tasdemir, Y., Birgisson, B. (2012). Low temperature cracking performance of WMA with the use of the superpave indirect tensile test. Construction and Building Materials, 30(3), 643-649. DOI 10.1016/j. conbuildmat.2011.12.013.

16. Wang, H., Hao, P. (2011). Numerical simulation of indirect tensile test based on the microstructure of asphalt mixture. Journal of Materials in Civil Engineering, 23(1), 21-29. DOI 10.1061/(ASCE)MT.1943-5533.0000037.

17. Birgisson, B., Montepara, A., Romeo, E., Tebaldi, G. (2011). Characterisation of asphalt mixture cracking behaviour using the three-point bending beam test. International Journal of Pavement Engineering, 12(6), 569-578. DOI 10.1080/10298436.2011.565766.

18. Saha, G., Biligiri, K. P. (2015). Fracture damage evaluation of asphalt mixtures using semi-circular bending test based on fracture energy approach. Engineering Fracture Mechanics, 142(8), 154-169. DOI 10.1016/j. engfracmech.2015.06.009.

19. Saha, G., Biligiri, K. P. (2016). Fracture properties of asphalt mixtures using semi-circular bending test: A state-ofthe-art review and future research. Construction and Building Materials, 105(2), 103-112. DOI 10.1016/j. conbuildmat.2015.12.046.

20. Wang, H., Zhang, C., Li, L., You, Z., Diab, A. (2016). Characterization of low temperature crack resistance of crumb rubber modified asphalt mixtures using semi-circular bending tests. Journal of Testing and Evaluation, 44(2), 847-855. DOI 10.1520/JTE20150145.

21. Xiang, L., Cheng, J., Que, G. (2009). Microstructure and performance of crumb rubber modified asphalt. Construction and Building Materials, 23(12), 3586-3590. DOI 10.1016/j.conbuildmat.2009.06.038.

22. Liang, M., Xin, X., Fan, W., Sun, H., Yao, Y. et al. (2015). Viscous properties, storage stability and their relationships with microstructure of tire scrap rubber modified asphalt. Construction and Building Materials, 74(3), 124-131. DOI 10.1016/j.conbuildmat.2014.10.015.

23. Zegeye, E., Le, J. L., Turos, M., Marasteanu, M. (2015). Investigation of size effect in asphalt mixture fracture testing at low temperature. Road Materials and Pavement Design, 13(sup1), 88-101. DOI 10.1080/ 14680629.2012.657064.

24. Wu, Y. T. (2017). Low-temperature rheological behavior of ultraviolet irradiation aged matrix asphalt and rubber asphalt binders. Construction and Building Materials, 157, 708-717. DOI 10.1016/j.conbuildmat.2017.09.039.

25. Wang, T., Xiao, F., Amirkhanian, S., Huang, W., Zheng, M. (2017). A review on low temperature performances of rubberized asphalt materials. Construction and Building Materials, 145(2), 483-505. DOI 10.1016/j. conbuildmat.2017.04.031. 